\title{
Improving the rainfall rate estimation in the midstream of the Heihe River Basin using raindrop size distribution
}

\author{
G. Zhao ${ }^{1}$, R. Chu ${ }^{1}$, T. Zhang ${ }^{1}$, J. Li $^{2}$, J. Shen ${ }^{1}$, and Z. Wu ${ }^{1}$ \\ ${ }^{1}$ Cold and Arid Regions Environmental and Engineering Research Institute, Chinese Academy of Sciences, \\ Lanzhou, 730000, China \\ ${ }^{2}$ Gansu Provincial Meteorological Bureau, Lanzhou, 730020, China
}

Received: 6 July 2009 - Published in Hydrol. Earth Syst. Sci. Discuss.: 24 September 2009

Revised: 1 January 2011 - Accepted: 30 January 2011 - Published: 16 March 2011

\begin{abstract}
During the intensive observation period of the Watershed Allied Telemetry Experimental Research (WATER), a total of 1074 raindrop size distribution were measured by the Parsivel disdrometer, the latest state-of-the-art optical laser instrument. Because of the limited observation data in Qinghai-Tibet Plateau, the modelling behaviour was not well done. We used raindrop size distributions to improve the rain rate estimator of meteorological radar in order to obtain many accurate rain rate data in this area. We got the relationship between the terminal velocity of the raindrop and the diameter (mm) of a raindrop: $v(D)=4.67 D^{0.53}$. Then four types of estimators for X-band polarimetric radar are examined. The simulation results show that the classical estimator $R\left(Z_{\mathrm{H}}\right)$ is most sensitive to variations in DSD and the estimator $R\left(K_{\mathrm{DP}}, Z_{\mathrm{H}}, Z_{\mathrm{DR}}\right)$ is the best estimator for estimating the rain rate. An X-band polarimetric radar (714XDP) is used for verifying these estimators. The lowest sensitivity of the rain rate estimator $R\left(K_{\mathrm{DP}}, Z_{\mathrm{H}}, Z_{\mathrm{DR}}\right)$ to variations in $\mathrm{DSD}$ can be explained by the following facts. The difference in the forward-scattering amplitudes at horizontal and vertical polarizations, which contributes $K_{\mathrm{DP}}$, is proportional to the $3 \mathrm{rd}$ power of the drop diameter. On the other hand, the exponent of the backscatter cross-section, which contributes to $Z_{\mathrm{H}}$, is proportional to the 6th power of the drop diameter. Because the rain rate $R$ is proportional to the 3.57th power of the drop diameter, $K_{\mathrm{DP}}$ is less sensitive to DSD variations than $Z_{\mathrm{H}}$.
\end{abstract}

Correspondence to: G. Zhao

(guozh@lzb.ac.cn)

\section{Introduction}

The quantitative estimation of rain rates using the meteorological radar has been one of the main themes in radar meteorology and radar hydrology. The conventional singlepolarized Doppler radar uses the measurement of radar reflectivity, radial velocity and the storm structure to infer some aspects of hydrometeor types and amounts. The relationships between the rain rate $R$ and the radar reflectivity factor $Z_{\mathrm{H}}$ $\left(Z_{\mathrm{H}}-R\right.$ relations) have been widely used to estimate rainfall amounts. However, the classic rain estimation method has many sources of error (e.g., Joss and Waldvogel, 1990; Collier, 1996). The sensitivity of $Z_{\mathrm{H}}-R$ relations to variations in raindrop size distributions (DSD) is the major source of error. Raindrop size distributions are determined by microphysical processes such as coalescence and breakup, condensation, evaporation and melting of snowflakes, etc. DSD also changes in time and space, in correspondence with changes in the microphysical process in a given precipitation system. Battan (1973) obtained a total of $69 Z_{\mathrm{H}}-R$ relationships to show that there was large variability in $Z_{\mathrm{H}}-R$ relationships caused by natural variations in DSD. Atlas et al. (1984) showed, from an analysis of experimental drop size spectra, that the average estimation error due to variations in DSD would be about $33 \%$.

With the advent of dual-polarized radar techniques it is generally possible to achieve significantly higher accuracies in the estimation of hydrometeor types and in some cases of hydrometeor amounts. In contrast to conventional radars, which use $Z_{\mathrm{H}}-R$ relationships to estimate rain rates, polarimetric radars use polarimetric parameters, such as differential reflectivity $Z_{\mathrm{DR}}$ and specific differential phase $K_{\mathrm{DP}}$. Because of being less sensitive to natural variations in the DSD, the polarimetric parameters are used in improving the

Published by Copernicus Publications on behalf of the European Geosciences Union. 
quantitative estimation of rain rates. Seliga and Bringi (1976) first showed that $Z_{\mathrm{DR}}$ could be used to retrieve raindrop size distributions and can improve rain rate estimation methods. The usage of differential phase to improve rain rate estimation was proposed theoretically (Seliga and Bringi, 1978) and is now recognized as an essential parameter for polarimetric radar measurements by Ryzhkov and Zrnic $(1995,1996)$. Most research in the field of radar polarimetry, as applied to rainfall parameter estimates, has been performed for the radar wavelengths at S-band, such as Sachidananda and $\mathrm{Zr}$ nic (1986), Chandrasekar et al. (1990). There are the wavelengths of operational radars in many countries (e.g., the Sband Weather Surveillance Radar-1988 Doppler (WSR-88D) network in the United States). Longer radar wavelengths (such as those at S-band) are the obvious choice for measurements in moderate and heavy rain because of low attenuation and backscatter phase shifts effects. Partial attenuation of radar signals is already a problem at C-band frequencies. Research studies on the C-band wavelength were done by May et al. (1999), Carey et al. (2000), Keenan et al. (2001) and Bringi et al. (2001a). Many researches and operational meteorological radars employ shorter wavelengths, such as those at X-band. The partial attenuation effects at X-band are more severe when compared with those at C-band, and accounting for these effects has been a significant problem for quantitative estimates of rainfall parameters based on reflectivity measurements at these wavelengths. Chandrasekar et al. (2002) analysed the error structure at the X-band, using a similar method as Chandrasekar et al. (1990) and showed that the $R\left(K_{\mathrm{DP}}\right)$ was relatively insensitive to $\mathrm{DSD}$ variations. A unique dataset consisting of high-resolution polarimetric radar measurements and dense rain gauge and disdrometer observations collected in east-central Florida during the summer of 1998 was examined by Brandes et al. (2002). All of the above validation studies have shown that there is an improvement in rainfall estimation if a dual-polarization radar is used and polarimetric rainfall estimation techniques are more robust with respect to DSD variations than the conventional $R\left(Z_{\mathrm{H}}\right)$ relations. At the moment, however, there is no consensus on the degree of improvement and the choice of an optimal polarization relation. The most significant improvement was reported in the latest study in Oklahoma (Ryzhkov et al., 2002) using the $R\left(K_{\mathrm{DP}}, Z_{\mathrm{DR}}\right)$ relation. Relatively modest improvement was observed in Florida (Brandes et al., 2002, 2003, 2004) with the best results obtained from the $R\left(Z_{\mathrm{H}}, Z_{\mathrm{DR}}\right)$ relation.

Scattering simulation is the most adequate method for clarifying the effect of DSD variations. This method is used in studies done by Sachidananda and Zrnic (1986), Chandrasekar et al. (1990) and Matrosov et al. (1999). In this work, we use three parameter distributions to study quantitatively the statistical errors of polarimetric rain rate estimators due to DSD variations, and use polarization radar parameters $Z_{\mathrm{DR}}$ and $K_{\mathrm{DP}}$ to improve the quantitative estimation of the rain rate.

\section{Objectives of the experiment}

The following scientific questions will be explored in this work.

1. The raindrop's terminal velocity is an important parameter in the microphysical process. The relationship between the terminal velocity and the raindrop size plays an important role in estimating the rain rate. This will be given in Sect. 4.2

2. Although the relationships between the rain rate $R$ and the radar reflectivity factor $Z_{\mathrm{H}}\left(Z_{\mathrm{H}}-R\right.$ relations) have been widely used to estimate rainfall amounts, they have many sources of error. Why $Z_{\mathrm{H}}-R$ relations are not one and only for rain rate estimating is also an important objective. The explanation will be given in Sect. 5 .

3. The polarimetric parameters are used in improving the quantitative estimation of rain rates. We get four types of estimators with polarimetric parameters to explain the polarimetric radar is superior to conventional singlepolarized Doppler radar in Sect. 6.

\section{Experiment}

The experiment area was carried out in the northeast of Qinghai-Tibet Plateau, $\left(38.85^{\circ} \mathrm{N}, 100.41^{\circ} \mathrm{E}\right)$, and the altitude is $1515 \mathrm{~m}$. This area is in the midstream of the Heihe basin. This basin is very important for the Northwestern China, because they are not only the bases of agriculture, but also offer a better microclimatic environment for developing the ecosystem. The arid region of the basin is one of the main arid regions in the world and its mountain topography forms the particular sight pattern of "glacier-riveroasis-desert" which is linked by water. The raindrop size data were collected from May to July 2008, during the second part of the Watershed Allied Telemetry Experimental Research (WATER) project (Li et al., 2009).

The disdrometer used is OTT Parsivel made by Germans. The new generation of Parsivel disdrometer provides the latest state-of-the-art optical laser technology. It is subsequently classified into 32 classes of sizes and terminal velocities. The OTT Parsivel has been described extensively by Yuter et al. (2006). An X-band polarimetric radar (714XDP) has a Vaisala Sigmet Digital IF Receiver and Signal Processor RVP8 was used in the Watershed Allied Telemetry Experimental Research(WATER) (Li et al., 2009) and thirty rain rate gauges were used for testing the rain rate estimators. In these raindrop distribution data and rain rate data, we made a distinction between stratiform and convective rainfall. Separation of convective and stratiform rain was carried out by visual inspection of RHIs from the X-band polarimetric radar. 
Table 1. The terminal velocity of the raindrop with different diameter.

\begin{tabular}{llllllllllll}
\hline \multicolumn{1}{c}{$\mathrm{D}(\mathrm{mm})$} & 0.31 & 0.44 & 0.56 & 0.68 & 0.81 & 1.19 & 1.63 & 2.13 & 2.38 & 4.25 \\
\hline $\begin{array}{l}\text { Observed } \\
\text { Result }(\mathrm{m} / \mathrm{s})\end{array}$ & $\mathrm{T}=293 \mathrm{~K}$ & 2.6 & 3.0 & 3.4 & 3.8 & 4.4 & 5.2 & 6.0 & 6.8 & 7.6 & 10.4 \\
\hline $\begin{array}{l}\text { Beard's } \\
\text { Result }(\mathrm{m} / \mathrm{s})\end{array}$ & $\begin{array}{l}\mathrm{T}=293 \mathrm{Kg} \mathrm{m}^{-3} \\
\rho=1.0 \mathrm{~kg} \mathrm{~m}^{-3}\end{array}$ & 1.26 & 1.87 & 2.42 & 2.95 & 3.52 & 4.94 & 6.16 & 7.29 & 7.78 & 9.74 \\
\hline
\end{tabular}

\section{Equations and analysis methods}

\subsection{Equations for the shape of a falling raindrop}

The shape of a falling raindrop in still air is determined by a balance of three types of forces working on the drop surface; hydrostatic pressure, surface tension and aerodynamic pressure. While a small drop has a spherical shape, a larger drop tends to have an oblate spheroid shape with a slightly flatter base. This characteristic of a raindrop shape is essential for polarimetric radar measurements of rainfall. The axis-ratio formulas used in the present study are:

$\alpha=1.0048+0.0057 D_{e}-2.628 D_{e}^{2}+3.682 D_{e}^{3}$

$-1.677 D_{e}^{4}, D_{e}<0.11 \mathrm{~cm}, D_{e}>0.44 \mathrm{~cm}$

$\alpha=1.012-0.144 D_{e}-1.03 D_{e}^{2}, 0.11 \mathrm{~cm} \leq D_{e} \leq 0.44 \mathrm{~cm}(2)$

where $D_{e}$ is the volume-equivalent spherical diameter (in centimetres). Equation (1) is for equilibrium axis ratios derived from the numerical model of Beard and Chuang (1987), and Eq. (2) is the axis ratio fit obtained from laboratory and field measurements by Andsager et al. (1999).

\subsection{Rain rate and terminal velocity of raindrops}

When the drop size distribution is given, the rain rate $R$ $\left(\mathrm{mmh}^{-1}\right)$ can be calculated by:

$R=0.6 \pi \times 10^{-3} \int_{D_{\min }}^{D_{\max }} D^{3} v(D) N(D) d D$

where $D$ is the diameter $(\mathrm{mm})$ of a raindrop, $D_{\max }$ is the maximum drop diameter, $v(D)$ is the terminal velocity $\left(\mathrm{ms}^{-1}\right)$ of the drop in still air and $N(D) d(D)$ the number of drops $\left(\mathrm{m}^{-3}\right)$ in the diameter interval $D$ to $D+d D$. Table 1 shows the terminal velocity of the raindrop with different diameters. There the terminal velocity and raindrop diameters are obtained from PASIVEL directly and it determines the terminal velocity and diameter as an approximate value. For example, if a raindrop's diameter is $0.2 \mathrm{~mm}$ which is smaller than the first measured value $(0.31 \mathrm{~mm})$, PASIVEL will determine the raindrop's diameter as $0.31 \mathrm{~mm}$. In Table 1 one point contained lots of raindrop diameters. The average atmospheric pressure of the ground was $840 \mathrm{mb}$ and

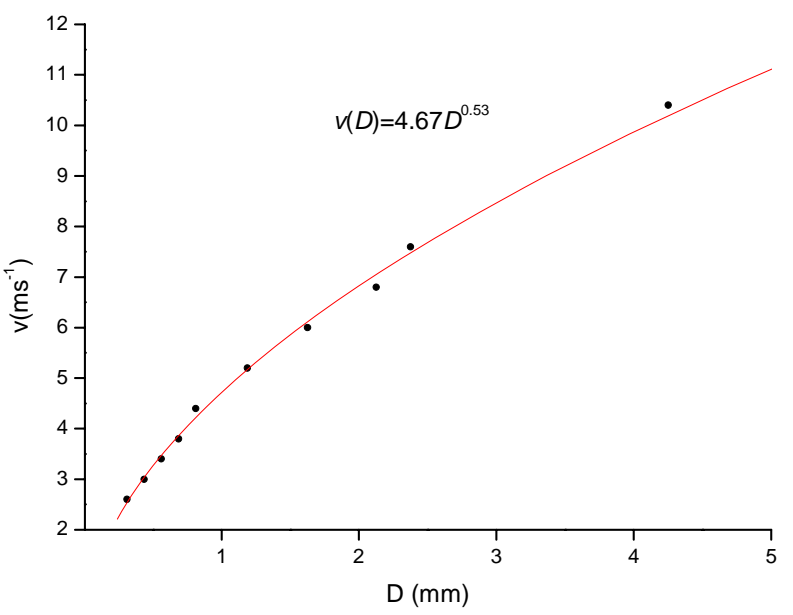

Fig. 1. The relationship between the raindrop diameter and the terminal velocity of the raindrop.

the average temperature on the ground was $20^{\circ} \mathrm{C}$ for these raindrop data. Then we measured the air density of the ground as $1.0 \mathrm{~kg} \mathrm{~m}^{-3}$. Beard (1976) obtained the resulting formulas for the terminal velocity in three diameter ranges $(0.5 \mu \mathrm{m}-19 \mu \mathrm{m}, 19 \mu \mathrm{m}-1.07 \mathrm{~mm}, 1.07 \mathrm{~mm}-7 \mathrm{~mm})$. These diameter ranges are used to calculate the terminal velocity directly from the equivalent spherical diameter and the physical properties of the drop and atmosphere. Foote and du Toit (1969) assumed the air density was reduced to a value of $0.66 \mathrm{~kg} \mathrm{~m}^{-3}$ at $500 \mathrm{mb}$. The velocity for large raindrops is seen to increase considerably from a sea level value of $9 \mathrm{~m} \mathrm{~s}^{-1}$ to a $500 \mathrm{mb}$ value in excess of $12 \mathrm{~m} \mathrm{~s}^{-1}$. We compared our result to the relation given by, for example, Beard. The result is also shown in Table 1 as follows. From the table, we found our observed terminal velocity was higher than Beard's result for the same temperature and air density. Figure 1 shows the curves using the method of least squares for the terminal velocity of the raindrop with different diameters. Obtain a relationship: $v(D)=4.67 D^{0.53}$. 


\subsection{Polarimetric parameters}

The reflectivity factor is defined by:

$Z_{H, V}=\frac{\lambda^{4}}{\pi^{5}}\left|\frac{m^{2}+1}{m^{2}-1}\right|^{2} \int_{D_{\min }}^{D_{\max }} \sigma_{H, V}(D) N(D) d D$

where $\lambda$ is the radar wavelength, $m$ the complex refractive index of water and $\sigma_{H, V}$ is the backscatter cross-section at horizontal and vertical polarizations.

The differential reflectivity $Z_{\mathrm{DR}}(\mathrm{dB})$ is defined by:

$Z_{\mathrm{DR}}=10 \log \left(\frac{Z_{H}}{Z_{V}}\right)=10 \log \left(\frac{\int_{D_{\min }}^{D_{\max }} \sigma_{H}(D) N(D) d D}{\int_{D_{\min }}^{D_{\max }} \sigma_{V}(D) N(D) d D}\right)$

The differential reflectivity $Z_{\mathrm{DR}}$ is a measure of the reflectivity-weighted mean axis ratio of the hydrometeors in a radar sampling volume which is defined by the radar beam width and the pulse width.

The specific differential phase $K_{\mathrm{DP}}\left(\mathrm{deg} \mathrm{km}{ }^{-1}\right)$ is defined by:

$K_{\mathrm{DP}}=\frac{180}{\pi} \lambda \operatorname{Re} \int_{0}^{D_{\max }}\left[f_{H}(D)-f_{V}(D)\right] N(D) d D$

where Re refers to the real part of the integral, $f_{\mathrm{H}}$ and $f_{\mathrm{V}}$ are the forward-scattering amplitudes at horizontal $(\mathrm{H})$ and vertical $(\mathrm{V})$ polarizations, respectively.

\section{Classic estimation methods of rain rate}

The sensitivity to natural variations in DSD is a substantial source of error in classic estimators of rain rate $R$. This is due to the fact that the $R-Z_{\mathrm{H}}$ relation is not a one-to-one relation; the same $Z_{\mathrm{H}}$ does not necessarily give the same $R$ and the same $R$ does not necessarily give the same $Z_{\mathrm{H}}$ because $Z_{\mathrm{H}}$ and $R$ depend on different moments of the DSD. Under Rayleigh scattering, $Z_{\mathrm{H}}$ is proportional to $D^{6}$ while $R$ is proportional to $D^{3.53}\left(v(D)=4.67 D^{0.53}\right)$. These facts can be explained by way of the observed DSD examples shown in Fig. $2 \mathrm{a}$ which has the approximate $Z_{\mathrm{H}}$ values but different rain rates $\left(4.3,6.7\right.$, and $\left.8.0 \mathrm{~mm} \mathrm{~h}^{-1}\right)$. The differences in the rain rate are due to the difference in the drop density of smaller drops; the DSD sample of $R=8.0 \mathrm{~mm} \mathrm{~h}^{-1}$ has a larger number of drops for $D=1-3 \mathrm{~mm}$ compared to the other DSD samples. Figure $2 b$ shows three examples of drop size distributions that have the same rain rate $R\left(0.2 \mathrm{~mm} \mathrm{~h}^{-1}\right)$, but different reflectivity factors $Z_{\mathrm{H}}(13,15$, and $16 \mathrm{dBZ}$ ). In contrast to the case of the rain rate, the difference in reflectivity factors can be explained by the difference in the number density of larger drops; the DSD sample of $Z_{\mathrm{H}}=16 \mathrm{dBZ}$ has the larger number density for the drops $D>1.5 \mathrm{~mm}$. This opposite dependency of $R$ and $Z_{\mathrm{H}}$ on drop size $D$ is due to the fact that $Z_{\mathrm{H}}$ is proportional to $D^{6}$, while $R$ is proportional to $D^{3.53}$.
Table 2a. Coefficients of the $R\left(Z, Z_{\mathrm{DR}}\right)$.

\begin{tabular}{lccc}
\hline Rain type & $\mathrm{a}$ & $\mathrm{b}$ & $\mathrm{c}$ \\
\hline Stratiform & 0.026 & 0.083 & -0.561 \\
Convective & 0.018 & 0.076 & -0.155 \\
\hline
\end{tabular}

Table 2b. Coefficients of the $R\left(K_{\mathrm{DP}}, Z, Z_{\mathrm{DR}}\right)$.

\begin{tabular}{lcccc}
\hline Rain type & $\mathrm{a}$ & $\mathrm{b}$ & $\mathrm{c}$ & $\mathrm{d}$ \\
\hline Stratiform & 0.009 & -0.173 & 0.103 & -0.653 \\
Convective & 0.198 & 0.4405 & 0.035 & -0.036 \\
\hline
\end{tabular}

$R$ and $Z_{\mathrm{H}}$ are dependent on different moments of the DSD. Thus, natural variations in DSD cause large dispersions in $R-Z_{\mathrm{H}}$ scatter plots. Classifying rain type (convective and stratiform rain) is one of the useful techniques for improving the accuracy of classic estimators $R\left(Z_{\mathrm{H}}\right)$. Scatter plots of $R-Z_{\mathrm{H}}$ relations is shown in Fig. 3, respectively, where $\mathrm{y}$-axis taking logarithm, for convective and stratiform rain. $R$ of each point are calculated directly from 30 secondaveraged DSD. From Fig. 3, we found $R$ and $Z_{\mathrm{H}}$ obey the relationship: $R=a \times 10^{b \times \mathrm{ZH}}$. The obtained $R-Z_{\mathrm{H}}$ relations for stratiform rain, convective rain and all rain types are $R=3.2 \times 10^{-2} \times 10^{0.058 \times \mathrm{ZH}}, R=4.6 \times 10^{-2} \times 10^{0.056 \times \mathrm{ZH}}$ and $R=3.0 \times 10^{-2} \times 10^{0.06 \times \mathrm{ZH}}$, respectively.

Several combinations of polarimetric variables are possible for constructing rain rate estimators. The simplest method is an estimator which uses only $K_{\mathrm{DP}}$. Scatter plots of $R-K_{\mathrm{DP}}$ relations is shown in Fig. 4, for stratiform rain and convective rain. From Fig. 4, we found $R$ and $K_{\mathrm{DP}}$ obey the relationship: $R=a+b K_{\mathrm{DP}}$. The obtained $R-K_{\mathrm{DP}}$ relations for stratiform rain and convective rain are $R=0.07907+1.74788 K_{\mathrm{DP}}$ and $R=0.027+2.122 K_{\mathrm{DP}}$, respectively.

It has been recognised for a long time that the X-band wavelength was not useful for accurate rainfall measurements because of the rain attenuation problem of $Z_{\mathrm{H}}$. However, this situation changed dramatically after polarimetric radar, which measures differential phase and the specific differential phase $K_{\mathrm{DP}}$, became available. In addition to the less sensitivity of differential phase to DSD variations, it is immune to radar hardware calibration problems, which are one of the major sources of error for signal power measurements and also immune to rain attenuation. Differential phase measurements are less affected by the presence of hail, which causes overestimation of the rain rate in the case of classic $R\left(Z_{\mathrm{H}}\right)$ estimator. The differential phase can be used to correct the reflectivity factor for loss due to beam blockage by topography, attenuation and anomalous propagations (Ryzhkov and Zrnic, 1996; Ryzhkov et 

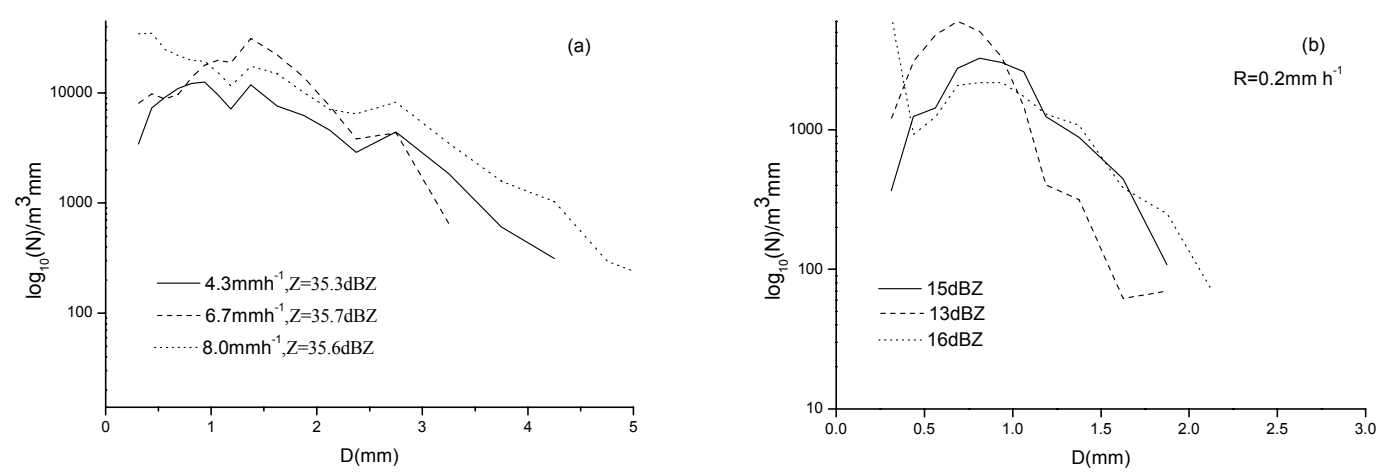

Fig. 2. The influence to the Z-R relationship by the changing of raindrop distribution.
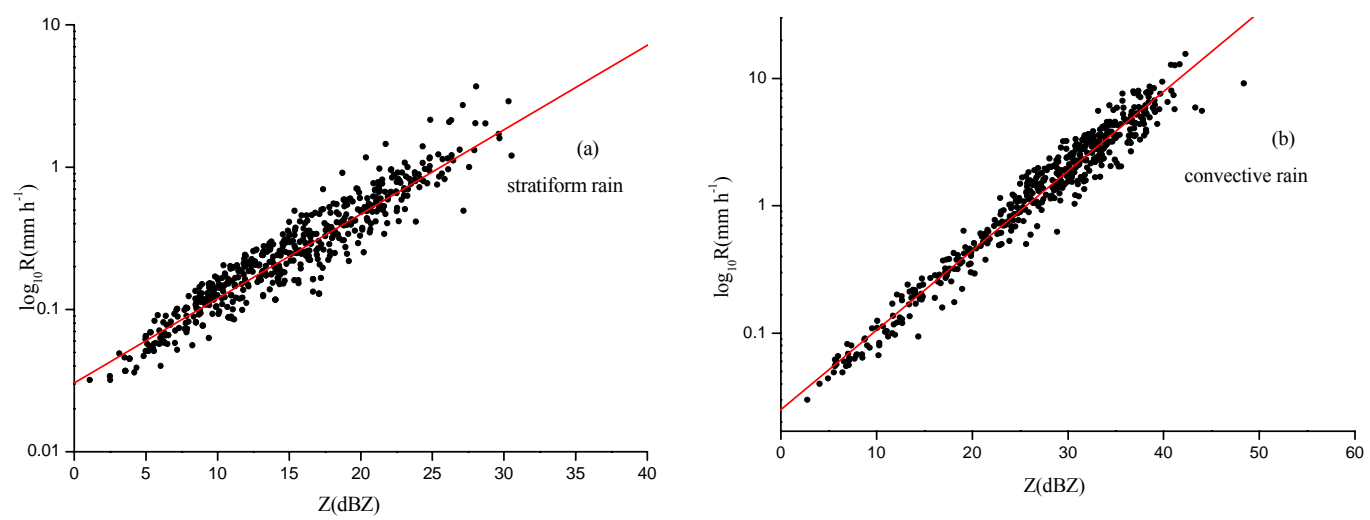

Fig. 3. Scatter plots of the radar reflectivity $(Z)$ and the rain rate $(R)$.
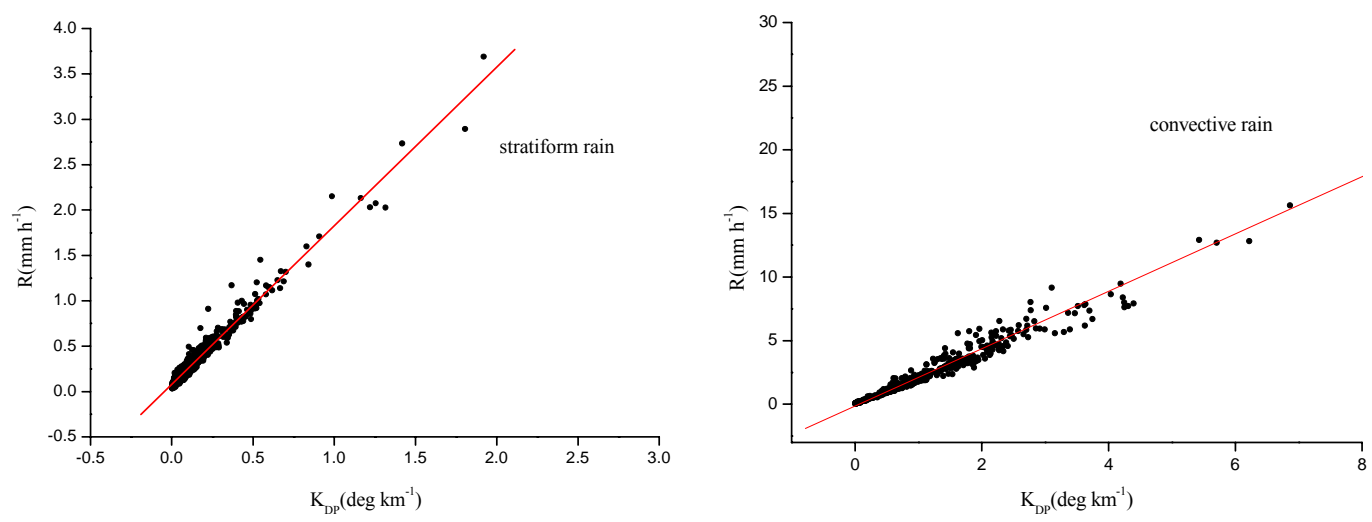

Fig. 4. Scatter plots of the specific differential phase $\left(K_{\mathrm{DP}}\right)$ and the rain rate $(R)$. 
al., 2000). Because of these advantages, it is important to construct rain estimators using a combination of polarimetric variables such as $R\left(Z_{\mathrm{H}}, Z_{\mathrm{DR}}\right)$ and $R\left(K_{\mathrm{DP}}, Z_{\mathrm{H}}, Z_{\mathrm{DR}}\right)$. So we use the relationships: $R=a \times 10^{b \times \mathrm{ZH}+c \times \mathrm{ZDR}}$ and

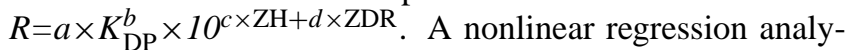
sis was applied to the data to obtain the coefficients of these estimators. The results are shown in Tables $2 \mathrm{a}$ and $\mathrm{b}$.

The comparisons of rain rates $R$ calculated from estimators $R\left(Z_{\mathrm{H}}\right), R\left(K_{\mathrm{DP}}\right), R\left(Z_{\mathrm{H}}, Z_{\mathrm{DR}}\right)$ and $R\left(K_{\mathrm{DP}}, Z_{\mathrm{H}}, Z_{\mathrm{DR}}\right)$ with rain rates $R_{\text {dis }}$ calculated from observed raindrop size spectra are shown in Figs. 5 and 6 for stratiform rain and convective rain, respectively. Scatter plots suggest that, of the four estimators, $R\left(K_{\mathrm{DP}}, Z_{\mathrm{H}}, Z_{\mathrm{DR}}\right)$ is the most accurate estimator from the viewpoint of the insensitivity to variations in DSD. The worst estimator is $R\left(Z_{\mathrm{H}}\right)$, which is most sensitive to variations in DSD.

To quantitatively examine the uncertainty of the four estimators, $R\left(Z_{\mathrm{H}}\right), R\left(K_{\mathrm{DP}}\right), R\left(Z_{\mathrm{H}}, Z_{\mathrm{DR}}\right)$ and $R\left(K_{\mathrm{DP}}\right.$, $\left.Z_{\mathrm{H}}, Z_{\mathrm{DR}}\right)$, due to the variations in DSD, two types of errors were calculated: The mean percentage normalized error (MPNE) and the mean percentage root-mean-squared error (MPRMSE). These errors are defined as:

$\mathrm{MPNE}=\sum_{n}\left\langle\left|R_{\mathrm{cal}}-R_{\mathrm{dis}}\right|\right\rangle /\left\langle R_{\mathrm{dis}}\right\rangle / n$

$\operatorname{MPRMSE}=\sum_{n} \sqrt{\left\langle\left(R_{\mathrm{cal}}-R_{\mathrm{dis}}\right)^{2}\right\rangle} /\left\langle R_{\mathrm{dis}}\right\rangle / n$

There, $R_{\text {cal }}$ means rain rates calculated from estimators, $R_{\text {dis }}$ means rain rates calculated from observed raindrop size spectra, $<>$ means the average for a certain interval of rain rate. We take the certain interval as $R<0.5\left(\mathrm{~mm} \mathrm{~h}^{-1}\right), 0.5 \leq R<1$, $1 \leq R<2,2 \leq R<4$ for stratiform rain, and $R<1\left(\mathrm{~mm} \mathrm{~h}^{-1}\right)$, $1 \leq R<2,2 \leq R<5,5 \leq R<10,10 \leq R<18$ for convective rain, $n$ means the number of the rain rate interval.

The MPNE of $R\left(Z_{\mathrm{H}}\right), R\left(K_{\mathrm{DP}}\right), R\left(Z_{\mathrm{H}}, Z_{\mathrm{DR}}\right)$ and $R\left(K_{\mathrm{DP}}, Z_{\mathrm{H}}, Z_{\mathrm{DR}}\right)$ for stratiform rain are $32.0 \%, 18.2 \%$, $15.0 \%$, and $12.3 \%$, respectively. The MPNE of $R\left(Z_{\mathrm{H}}\right)$, $R\left(K_{\mathrm{DP}}\right), R\left(Z_{\mathrm{H}}, Z_{\mathrm{DR}}\right)$ and $R\left(K_{\mathrm{DP}}, Z_{\mathrm{H}}, Z_{\mathrm{DR}}\right)$ for convective rain are $28.8 \%, 16.8 \%, 14.2 \%$ and $11.3 \%$, respectively. The MPRMSE of $R\left(Z_{\mathrm{H}}\right), R\left(K_{\mathrm{DP}}\right), R\left(Z_{\mathrm{H}}, Z_{\mathrm{DR}}\right)$ and $R\left(K_{\mathrm{DP}}\right.$, $\left.Z_{\mathrm{H}}, Z_{\mathrm{DR}}\right)$ for stratiform rain are $33.2 \%, 19.1 \%, 15.1 \%$ and $13.3 \%$, respectively. The MPRMSE of $R\left(Z_{\mathrm{H}}\right), R\left(K_{\mathrm{DP}}\right)$, $R\left(Z_{\mathrm{H}}, Z_{\mathrm{DR}}\right)$ and $R\left(K_{\mathrm{DP}}, Z_{\mathrm{H}}, Z_{\mathrm{DR}}\right)$ for convective rain are $30.8 \%, 16.9 \%, 14.0 \%$ and $10.3 \%$, respectively. From these comparisons, we can conclude that $R\left(K_{\mathrm{DP}}, Z_{\mathrm{H}}, Z_{\mathrm{DR}}\right)$ is the least sensitive to variations in DSD.

Although error analysis based on the comparisons of radar estimates with gauge measurements is not necessarily an appropriate method to confirm the sensitivity of rain rate estimators to variations in DSD, it may be useful to know the total performance of rain rate estimators. The values of errors obtained from the radar-gauge analysis are usually larger than those of the simulation because error sources other than
DSD variations can be commonly introduced: for example, errors due to the difference in time and space for measurements, due to evaporation, or due to attenuation correction of $Z_{\mathrm{H}}$ and $Z_{\mathrm{DR}}$. From the comparison of radar estimated rainfall amount with rain gauge data, Park et al. (2005) showed that the normalized error of attenuation corrected $R\left(Z_{\mathrm{H}}\right)$, and the normalized error of $R\left(K_{\mathrm{DP}}\right)$ are $26 \%$ and $21 \%$, respectively, for 15-min rainfall accumulations and $19 \%$ and $11 \%$, respectively, for one-hour rainfall accumulations.

There is a convective rain process and eight gauges received rain rate data on 13 June 2008.

We used the X-band polarimetric radar and these gauges to test rain rate estimators. The radar data quality has been corrected before used. The shape of raindrops can be approximated by oblate spheroids for light rain. Radar and in situ aircraft-based observations show that, on average, the raindrops are oriented with the symmetry axis in the vertical direction. This implies that the shape of raindrops seen at an elevation angle of 90 is nearly circular. Therefore, $Z_{\mathrm{DR}}$ measurements performed with the antenna pointing at an elevation of 90 should be $0 \mathrm{~dB}$. However, if there is nonzero $Z_{\mathrm{DR}}$ due to the system bias, it does not change with the different $\mathrm{H}$ and $\mathrm{V}$ orientations looking vertical. In many radars, the different $\mathrm{H}$ and $\mathrm{V}$ orientations can be achieved by changing the azimuth positioning over zero to 360 , keeping the elevation angle at 90 . However, the exact procedure depends on the set up of the scanning servo system of the radar. In summary, the average $Z_{\mathrm{DR}}$ computed with all possible orientations of the polarization states of the radar antenna pointing in the vertical direction should be zero. Figure 7 shows the meanvalue of the $Z_{\mathrm{DR}}$ is 0.6 for $88^{\circ}$ elevation. This is the system deviation. It is well known that convective storms cause significant attenuation and differential attenuation at X-band. As a consequence, radar measurements of reflectivity and differential reflectivity must be corrected for rain attenuation before they can be used quantitatively. In addition, Polarimetric radars at $\mathrm{X}$-band have one important advantage, the specific differential phase $K_{\mathrm{DP}}$ is much larger than that at longer wavelengths. From scattering simulations, compared to $\mathrm{C}$ and S-bands, respectively, $K_{\mathrm{DP}}$ at $\mathrm{X}$-band is larger by about 1.5 and 3 times for the same rain rate. We used the $K_{\mathrm{DP}}$ to correct the attenuated $Z_{\mathrm{H}}$ and $Z_{\mathrm{DR}}$ (Bringi, 2001b). The specific attenuation $\left(A_{\mathrm{H}}\right)$ and the specific differential attenuation $\left(A_{\mathrm{DP}}\right)$ can be obtained as follows:

$$
\begin{array}{ll}
A_{\mathrm{H}}=\alpha \cdot Z_{H}^{\beta} & \left(Z_{\mathrm{H}}<25 d B z\right) \\
A_{\mathrm{H}}=a_{1} \cdot K_{\mathrm{DP}} & \left(Z_{\mathrm{H}} \geq 25 d B z\right) \\
A_{\mathrm{DP}}=\gamma \cdot A_{H}^{d} & \left(Z_{\mathrm{H}}<25 d B z\right) \\
A_{\mathrm{DP}}=a_{2} \cdot K_{\mathrm{DP}} & \left(Z_{\mathrm{H}} \geq 25 d B z\right)
\end{array}
$$

Then, $Z_{\mathrm{H}}$ and $Z_{\mathrm{DR}}$ can be corrected as follows:

$Z_{\mathrm{H}}(r)=Z_{\mathrm{Ha}}(r)+2 \int_{0}^{r} A_{\mathrm{H}}(s) d s$ 

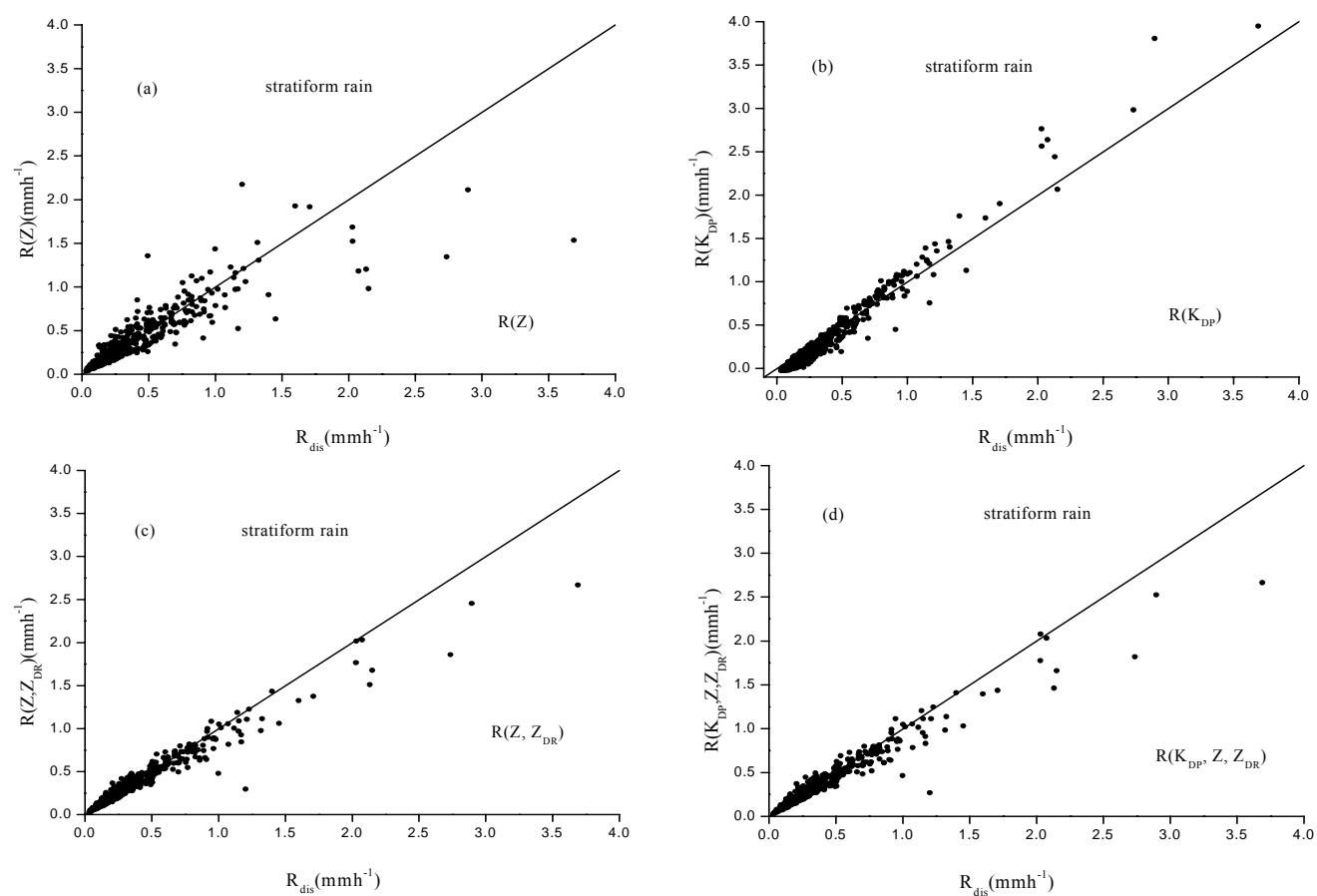

Fig. 5. Scatter plots of $\mathrm{R}_{\text {dis }}$ calculated from measured drop size distribution and $R$ estimated by four types for rain rate estimators (a) $R(Z)$, (b) $R\left(K_{\mathrm{DP}}\right)$, (c) $R\left(Z, Z_{\mathrm{DR}}\right)(\mathrm{d}) R\left(K_{\mathrm{DP}}, Z, Z_{\mathrm{DR}}\right)$.
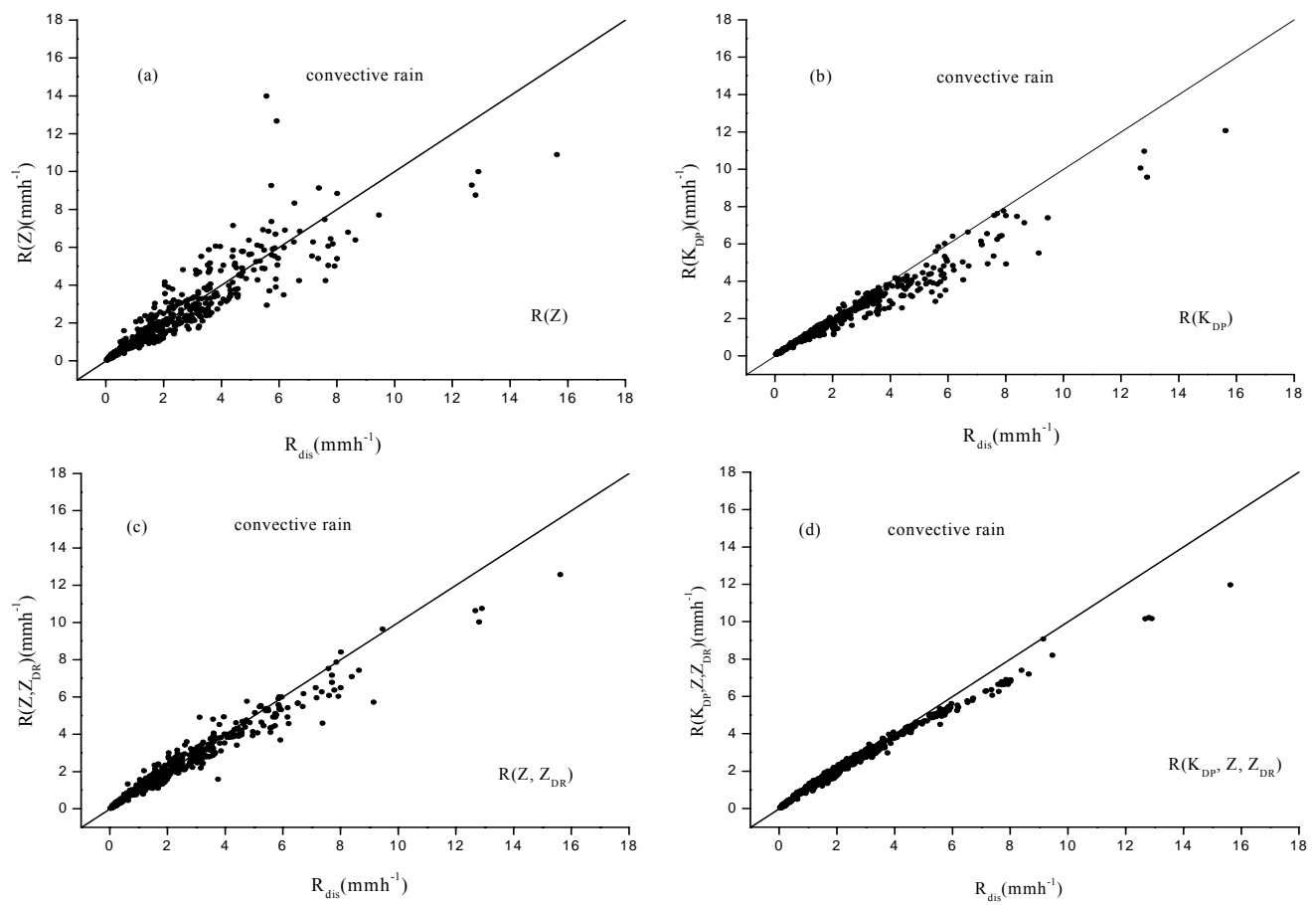

Fig. 6. Scatter plots of $R_{\text {dis }}$ calculated from measured drop size distribution and $R$ estimated by four types for rain rate estimators (a) $R$ ( $Z$ ), (b) $R\left(K_{\mathrm{DP}}\right)$, (c) $R\left(Z, Z_{\mathrm{DR}}\right)(\mathbf{d}) R\left(K_{\mathrm{DP}}, Z, Z_{\mathrm{DR}}\right)$. 
Table 3. The reliability of the rainfall estimators.

\begin{tabular}{lccccccc}
\hline $\begin{array}{l}\text { Rain } \\
\text { gauge }\end{array}$ & $Z_{\mathrm{H}}(\mathrm{dBZ})$ & $Z_{\mathrm{DR}}(\mathrm{dB})$ & $K_{\mathrm{DP}}\left(\mathrm{deg} \mathrm{km}^{-1}\right)$ & $R(Z) / \mathrm{NE}$ & $R\left(Z, Z_{\mathrm{DR}}\right) / \mathrm{NE}$ & $R\left(Z, Z_{\mathrm{DR}}, K_{\mathrm{DP}}\right) / \mathrm{NE}$ & $R_{\text {gauge }}$ \\
\hline NO.03 & 29 & 0.8 & 1.2 & $1.9 / 17 \%$ & $2.1 / 8 \%$ & $2.0 / 13 \%$ & 2.3 \\
NO.05 & 35 & 1.4 & 0.3 & $4.1 / 46 \%$ & $4.9 / 75 \%$ & $2.0 / 28 \%$ & 2.8 \\
NO.11 & 35 & 1.9 & 1.4 & $4.1 / 2 \%$ & $4.2 / 5 \%$ & $4.5 / 12 \%$ & 4.0 \\
NO.12 & 31 & 1.0 & 0.3 & $2.5 / 21 \%$ & $2.8 / 12 \%$ & $3.8 / 18 \%$ & 3.2 \\
NO.14 & 38 & 2.0 & 2.2 & $6.1 / 39 \%$ & $6.3 / 43 \%$ & $4.7 / 7 \%$ & 4.4 \\
NO.19 & 35 & 1.3 & 2.9 & $4.1 / 29 \%$ & $5.1 / 12 \%$ & $5.9 / 2 \%$ & 5.8 \\
NO.26 & 23 & 1.3 & 0.6 & $0.7 / 75 \%$ & $0.38 / 5 \%$ & $0.31 / 22 \%$ & 0.4 \\
NO.29 & 35 & 4.6 & 1.6 & $4.5 / 26 \%$ & $5.3 / 13 \%$ & $6.0 / 1 \%$ & 6.1 \\
\hline
\end{tabular}

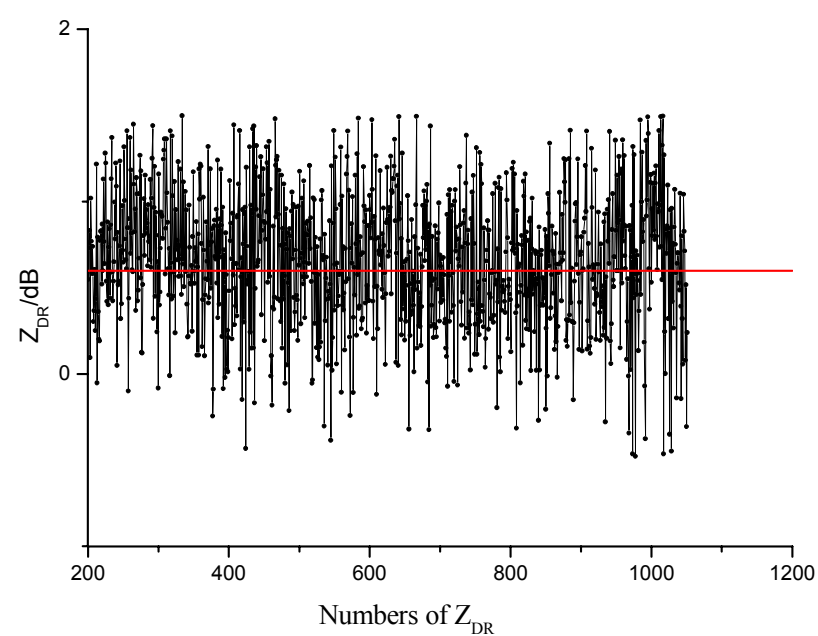

Fig. 7. Meanvalue of the $Z_{\mathrm{DR} / \mathrm{dB}}$ for $88^{\circ}$ elevation.

$Z_{\mathrm{DR}}(r)=Z_{\mathrm{DRa}}(r)+2 \int_{0}^{r} A_{\mathrm{DP}}(s) d s$

Table 3 is given for testing the rain rate estimators. In Table 3 , $Z_{\mathrm{H}}, Z_{\mathrm{DR}}, K_{\mathrm{DP}}$ are the radar observations above the rain rate gauges and $R_{\text {gauge }}$ is the rain rate gauges observation. The rain rate estimators' normalized error (NE), also given in Table 3 , shows that the polarimetric rain rate estimators that are obtained from DSD can well enhance the precision of rain rate estimate.

\section{Summary}

The present study used a total of 1.074 thirty secondaveraged raindrop size spectra, measured with a Parsivel disdrometer to calculate the radar reflectivity factor $Z_{\mathrm{H}}$, the specific differential phase $K_{\mathrm{DP}}$, and the differential reflectivity $Z_{\mathrm{DR}}$. Then, we get four types of rain rate estimators $R\left(Z_{\mathrm{H}}\right)$, $R\left(K_{\mathrm{DP}}\right), R\left(Z_{\mathrm{H}}, Z_{\mathrm{DR}}\right)$ and $R\left(K_{\mathrm{DP}}, Z_{\mathrm{H}}, Z_{\mathrm{DR}}\right)$ with these parameters. We quantify the sensitivity of four types of rain rate estimators to natural variations in DSD. Most of the previous studies evaluated polarimetric estimators, comparing radar estimates with surface gauge measurements. It is well known that the difference between radar estimates and rain gauge data is due not only to the accuracy of the rain rate estimator to variations in DSD, but also to other factors, such as differences in the sampling volume size, differences in the observation height, accuracy of the radar system calibration, etc. The results of our simulations show that the estimator $R\left(K_{\mathrm{DP}}, Z_{\mathrm{H}}, Z_{\mathrm{DR}}\right)$ is less sensitive to natural variations in DSD than the classical estimator $R\left(Z_{\mathrm{H}}\right)$. The mean percentage normalized error (MPNE) of $R\left(Z_{\mathrm{H}}\right)$ and $R\left(K_{\mathrm{DP}}\right.$, $\left.Z_{\mathrm{H}}, Z_{\mathrm{DR}}\right)$ for stratiform rain and convective rain are $32.0 \%$, $12.3 \%$ and $28.8 \%, 11.3 \%$, respectively. The mean percentage root-mean-squared error (MPRMSE) which is also used to quantify the statistical error of stratiform rain and convective rain are $33.2 \%, 13.3 \%$ and $30.8 \%, 10.3 \%$, respectively. The lower sensitivity of $R\left(K_{\mathrm{DP}}, Z_{\mathrm{H}}, Z_{\mathrm{DR}}\right)$ and the higher sensitivity of $R\left(Z_{\mathrm{H}}\right)$ to variations in DSD can be explained by the fact that the difference between the forward-scattering amplitudes at horizontal $(\mathrm{H})$ and vertical $(\mathrm{V})$ polarizations $f_{\mathrm{H}}(D)-f_{\mathrm{V}}(D)$ in the definition of $K_{\mathrm{DP}}$ is proportional to the 3rd power of the diameter of a raindrop for the monodisperse DSD model, while the reflectivity factor $Z_{\mathrm{H}}$ is proportional to the 6th power of the diameter.

Acknowledgements. This work is supported by the CAS (Chinese Academy of Sciences) Action Plan for West Development Project "Watershed Allied Telemetry Experimental Research (WATER)" (Grant No.: KZCX2-XB2-09) and the National Natural Science Foundation of China (Grant No.: 40575008). Generous help in revising the paper was provided by the editors and reviewers, especially K. Roth and H. Leijnse.

Edited by: K. Roth 


\section{References}

Atlas, D., Ulbrich, C. W., and Meneghini, R.: The multi-parameter remote measurement of rainfall, Radio Sci., 19, 3-22, 1984.

Andsager, K., Beard, K. V., and Laird, N. F.: Laboratory measurements of axis ratios for large drops, J. Atmos. Sci., 56, 26732683, 1999.

Battan, L. J.: Radar observation of the atmosphere, Univ. Chicago Press, 324 pp., 1973.

Beard, K. V. and Chuang, C.: A new model for the equilibrium shape of raindrops, J. Atmos. Sci., 44, 1509-1524, 1987.

Beard, K. V.: Terminal velocity and shape of cloud and precipitation drops aloft, J. Atmos. Sci., 33, 851-864, 1976.

Brandes, E. A., Zhang, G., and Vivekanandan, J.: Experiments in rainfall estimation with polarimetric radar in a subtropical environment, J. Appl. Meteorol., 41, 674-685, 2002.

Brandes, E. A., Zhang, G., and Vivekanandan, J.: An evaluation of a drop distribution based polarimetric radar rainfall estimator, J. Appl. Meteor., 42, 652-660, 2003.

Brandes, E. A., Zhang, G., and Vivekanandan, J.: Drop-size distribution retrieval with polarimetric radar: model and application, J. Appl. Meteor., 43(3), 461-475, 2004.

Bringi, V. N. and Chandrasekar, V.: Polarimetric Doppler weather radar, Cambridge Univ. Press, 636 pp., 2001a.

Bringi, V. N, Keenan, T. D., and Chandrasekar, V.: Correcting C band radar reflectivity and differential reflectivity data for rain attenuation: A self-consistent method with constraints, IEEE Trans. Geosci. Remote. Sens., 39, 1906-1915, 2001 b.

Carey, L. C., Rutledge, S. A., Ahijevych, D. A., and Keenan, T. D.: Correcting propagation effects in C-band polarimetric radar observations of tropical convection using differential propagation phase, J. Appl. Meteor., 39, 1405-1433, 2000.

Chandrasekar, V., Bringi, V. N., Balakrishnan, N., and Zrnic, D. S.: Error structure of multiparameter radar and surface measurements of rainfall. Part III: Specific differential phase, J. Atmos. Oceanic Technol., 7, 621-629, 1990.

Chandrasekar, V., Gorgucci, E., and Bringi, V. N.: Evaluation of polarimetric radar rainfall algorithms at X-band, Proc. 2nd European Conf. on Radar Meteorology (ERAD), Delft, Netherlands, 277-281, 2002.

Collier, C. G.: Applications of Weather Radar Systems. A Guide to Uses of Radar Data in Meteorology and Hydrology. 2nd edn., John Wiley \& Sons, 390 pp., 1996.

Foote, G. B. and du Toit, P. S.:Terminal fellspeeds of raindrops aloft, J. Appl. Meteor., 8, 249-253, 1969.

Joss, J. and Waldvogel, A.: Precipitation measurements and hydrology, Radar in Meteorology, edited by: Atlas, D., Am. Meteor. Soc., 577-606, 1990.
Keenan, T. D., Zrnic, D. S., Carey, L., and May, P.: Sensitivity of 5-cm wavelength polarimetric radar variables to raindrop axial ratio and drop size distribution, J. Appl. Meteor., 40, 526-545, 2001.

Li, X., Li, X. W., Li, Z. Y., Ma, M. G., Wang, J., Xiao, Q., Liu, Q., Che, T., Chen, E. X., Yan, G. J., Hu, Z. Y., Zhang, L. X., Chu, R. Z., Su, P. X., Liu, Q. H., Liu, S. M., Wang, J. D., Niu, Z., Chen, Y., Jin, R., Wang, W. Z., Ran, Y. H., Xin, X. Z. and Ren, H. Z.: Watershed Allied Telemetry Experimental Research, J. Geophys. Res., 114, D22103, doi:10.1029/2008JD011590, 2009.

Matrosov, S. Y., Kropfli, R. A., Reinking, R. F., and Martner, B. E.: Prospects for measuring rainfall using propagation differential phase in X- and Ka-radar bands, J. Appl. Meteorol., 38, 766776, 1999.

May, P. T., Keenan, T. D., Zrnic, D. S., Carey, L. D., and Rutledge, S. A.: Polarimetric radar measurements of tropical rain at a $5-\mathrm{cm}$ wavelength, J. Appl. Meteor., 38, 750-765, 1999.

Park, S. G., Maki, M., Iwanami, K., Bringi, V. N., and Chandrasekar, V.: Correction of radar reflectivity and differential reflectivity for rain attenuation at X-band. Part II: Evaluation and application, J. Atmos. Oceanic. Technol., 22, 1633-1655, 2005.

Ryzhkov, A. V. and Zrnic, D. S.: Comparison of dual-polarization radar estimators of rain, J. Atmos. Oceanic. Technol., 12, 249256, 1995.

Ryzhkov, A. V. and Zrnic, D. S.: Assessment of rainfall measurement that uses specific differential phase, J. Appl. Meteor., 35, 2080-2090, 1996.

Ryzhkov, A. V., Zrnic, D. S., and Fulton, R.: Areal rainfall estimates using differential phase, J. Appl. Meteor., 39, 263-268, 2000.

Ryzhkov, A. V., Schuur, T. J., and Zrnic, D. S.: Testing a polarimetric rainfall algorithm and comparison with a dense network of rain gauges, Hydrological Resources on Hydrological Applications of Weather Radar, Kyoto, Japan, 159-164, 2002.

Sachidananda, M. and Zrnic, D. S.: Differential propagation phase shift and rainfall rate estimation, Radio Sci., 21, 235-247, 1986.

Seliga, T. A. and Bringi, V. N.: Potential use of radar differential reflectivity measurements at orthogonal polarizations for measuring precipitation, J. Appl. Meteorol., 15, 69-76, 1976.

Seliga, T. A. and Bringi, V. N.: Differential reflectivity and differential phase shift: Applications in radar meteorology, Radio Sci., 13, 271-275, 1978.

Yuter, S. E., Kingsmill, D. E., Nance, L. B., and Löffler-Mang, M.: Observations of precipitation size and fall speed characteristics within coexisting rain and wet snow, J. Appl. Meteorol. Climatol., 45, 1450-1464, 2006. 